\title{
Innovaciones educativas 2016. Educar para la sociedad digital
}

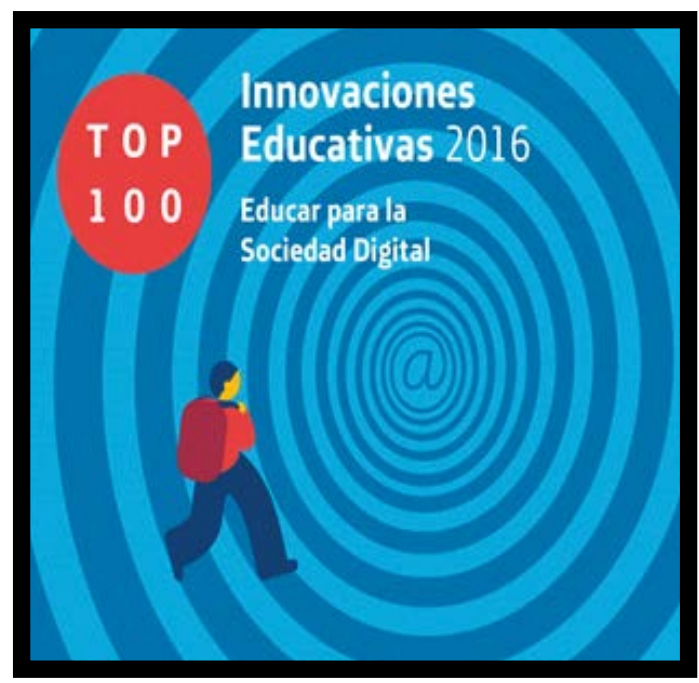

Fundación Telefónica. 2016. Innovaciones educativas 2016. Educar para la sociedad digital. http://www.fundaciontelefonica.com/ educacion_innovacion/desafio_educacion/

La educación debe ser soporte de igualdad y justicia social. Debe facilitar tanto el desarrollo personal como la integración social. El momento histórico al que se enfrenta la educación en la actualidad es fascinante. La revolución digital está generando, de modo incremental y acelerado, transformaciones en todos los ámbitos de la sociedad. La educación no está exenta de estos cambios. Al contrario, es donde más críticos son sus efectos. Por ello, es urgente que los conozcamos mejor y que consigamos que la educación no sólo se adapte, sino que se anticipe a ellos. Lo que se ha venido denominando Sociedad Digital hace referencia a una sociedad que se caracteriza por ser abierta, cambiante, conectada y global. En ella, los alumnos son colaborativos, sus ideas compiten en igualdad de condiciones. Cuenta más el valor de la contribución que el de la posición. Los alumnos no esperan clases magistrales, sino conversaciones abiertas.
Adicionalmente, predomina la necesidad de aprender de forma activa, incluso "aprender haciendo": no quieren roles pasivos. Buscan participar activamente en todo el proceso educativo, empezando por el propio diseño de sus estudios. La pasión, la creatividad y la iniciativa toman el protagonismo. Ello implica, por tanto, la personalización de los itinerarios formativos para todos y en todas partes.

Fundación Telefónica está comprometida con este proceso de transformación de la educación. Nuestro objetivo es detectar y analizar las nuevas tendencias educativas, evaluar su impacto, comprender y dar a conocer sus implicaciones en los procesos pedagógicos y trasladarlas a los entornos sociales más desprotegidos.

"Explorar para Inspirar para Transformar" es el eje vertebrador de nuestra actividad. El presente informe recoge los resultados del proyecto Top 100 Innovaciones Educativas 2016. Se trata de una amplia investigación que Fundación Telefónica ha llevado a cabo a lo largo de este año para identificar iniciativas educativas innovadoras que han demostrado su eficacia para mejorar las competencias de 
los estudiantes para enfrentarse a los retos que plantea la Sociedad Digital.

Se presentan las iniciativas que se consideran con mayor potencial de desarrollo, y para cada una de ellas se ofrece información breve pero útil y sistemática. Estamos seguros de que estos resultados serán una herramienta que permitirá difundir un conocimiento que consideramos de gran valor para toda la comunidad educativa $\mathrm{y}$ la sociedad en general. 